\title{
Analisis Tegangan Pada Mata Pahat Dalam Proses Pemesinan Bubut Menggunakan Software Autodesk Inventor 2016
}

\author{
Ismail Thamrin., Astuti, Ellyanie, Al Fiqhi. Meizan Twista Herbian \\ Jurusan Teknik Mesin Fakultas Teknik Universitas Sriwijaya \\ J1. Raya Palembang - Prabumulih Km 32, Ogan Ilir, Sumatera Selatan, Indonesia \\ Email : ismailthamrin72@gmail.com
}

\begin{abstract}
In the turning process, all the energy used for chip formation is converted into heat. This causes the temperature at the cutting zone will increase. The heat generated during the machining process depends on the type of tool material, workpiece material, and process parameters such as cutting speed, cutting depth and feeding. High temperatures that are well distributed during the turning process, have an important effect on the tension on the tools. Therefore, it is necessary to analyze the effect of variation of the rake angle on titanium machining process, by comparing the theoretical and simulation results using Autodesk Inventor 2016. In this research, the cutting force used was orthogonal. The main angle variations are used $5^{\circ}, 10^{\circ}$ and $15^{\circ}$. Based on the theoretical, the maximum cutting force $(\mathrm{Fc})$ is $1720 \mathrm{~N}$ for the rake angle $(\gamma) 5^{\circ}$, and there is a decrease in the cutting force of each rake angle $(\gamma)$ increase. From the simulation results, the maximum tension occurs at a rake angle of $15^{\circ}$, amounting to $1368.462 \mathrm{~N} / \mathrm{mm} 2$. There is an increase in the tension of each rake angle $(\gamma)$ increase.
\end{abstract}

Keywords: orthogonal cutting, temperature distribution, thermal stress

\begin{abstract}
Abstrak
Pada proses bubut, seluruh energi yang digunakan untuk pembentukan geram diubah menjadi kalor. Hal ini menyebabkan suhu pada zona pemotongan akan meningkat. Kalor yang dibangkitkan selama proses pemesinan bergantung terutama pada jenis pahat, material benda kerja, dan parameter proses seperti kecepatan potong, kedalaman potong dan gerak makan. Temperatur tinggi yang terdistribusi dengan baik selama proses pembubutan, memiliki pengaruh yang penting terhadap tegangan pada mata pahat. Maka dari itu perlu dilakukan analisa pengaruh sudut geram terhadap tegangan pada proses pembubutan titanium dengan cara mengkomparasi hasil teoritis dan simulasi menggunakan Autodesk Inventor 2016. Pada penelitian ini, gaya pemotongan yang digunakan adalah pemotongan orthogonal. Variasi sudut utama pemotongan yang digunakan $5^{\circ}, 10^{\circ}$ dan $15^{\circ}$. Berdasarkan dari perhitungan secara teoritis, gaya potong maksimum $\left(F_{c}\right)$ yaitu $1720 \mathrm{~N}$ untuk sudut geram $(\gamma) 5^{0}$, dan terjadi penurunan gaya potong setiap kenaikan sudut geram $(\gamma)$. Dari hasil simulasi yang dilakukan, tegangan maksimum terjadi pada sudut potong $15^{\circ}$, sebesar $1368,462 \mathrm{~N} / \mathrm{mm}^{2}$, terjadi kenaikan tegangan setiap kenaikan sudut geram $(\gamma)$.
\end{abstract}

Kata Kunci : pemotongan orthogonal, distribusi temperature, tegangan thermal

\section{LATAR BELAKANG}

Proses Turning adalah proses pemesinan pada permukaan benda kerja yang menghasilkan geometri silinder. kenaikan temperature pada kontak pahat dan benda kerja adalah salah satu parameter penting pada analisa proses turning. Temperatur pemotongan timbul akibat panas yang dihasilkan oleh deformasi material dari perautan benda kerja, gesekan antara pahat dan benda kerja dan gesekan antara pahat dan geram [1].

Dalam proses pemesinan, suhu pemotongan dan gaya pemotongan merupakan parameter penting yang harus dikontrol atau dikurangi. Suhu pemotongan dan gaya pemotongan akan berpengaruh terhadap umur pahat sehingga mempengaruhi biaya produksi (cost). Besarnya gaya pemotongan merupakan informasi yang sangat penting dalam perencenaan pemesinan. Gaya pemotongan faktor yang sangat diperhitungkan dalam menganalisa dan mengembangkan perangkat untuk mendapatkan gaya potong. Hal ini yang kemudian menimbulkan tegangan yang terjadi antara pahat potong dan juga benda kerja [2].

Keausan pahat dapat dipengaruhi geometri pahat, selain itu juga dipengaruhi oleh faktor - faktor proses pemesinan antara lain jenis bahan benda kerja dan pahat, kondisi (parameter) pemotongan (kecepatan potong, kedalaman pemotongan, dan gerak makan), cairan pendingin, dan jenis dari proses pemesinan [3]. Saat proses pembubutan, kecepatan potong, gerak makan, dan kedalaman pemotongan akan mempengaruhi besarnya tegangan yang terjadi pada proses pemotongan. Makin besar gaya potong maka akan memperbesar suhu kontak antara benda 
kerja dengan mata pahat. Hal ini dapat membuat pahat lebih cepat mengalami keausan. Dengan begitu, besaran gaya potong ataupun tegangan pada proses pembubutan menjadi penting untuk diketahui. Perhitungan tegangan didapatkan dengan cara mengukur gaya pemotongan mesin bubut nantinya dapat digunakan untuk mengoptimalkan proses pemesinan di mesin bubut [4]

\section{METODE PENELITIAN}

Gambar 1 dan Gambar 2 menunjukkan tata alir pelaksanaan penelitian dan simulasi yang dilakukan. Sebelum melaksanakan penelitian, terlebih dahulu dilakukan simulasi menggunakan software inventor

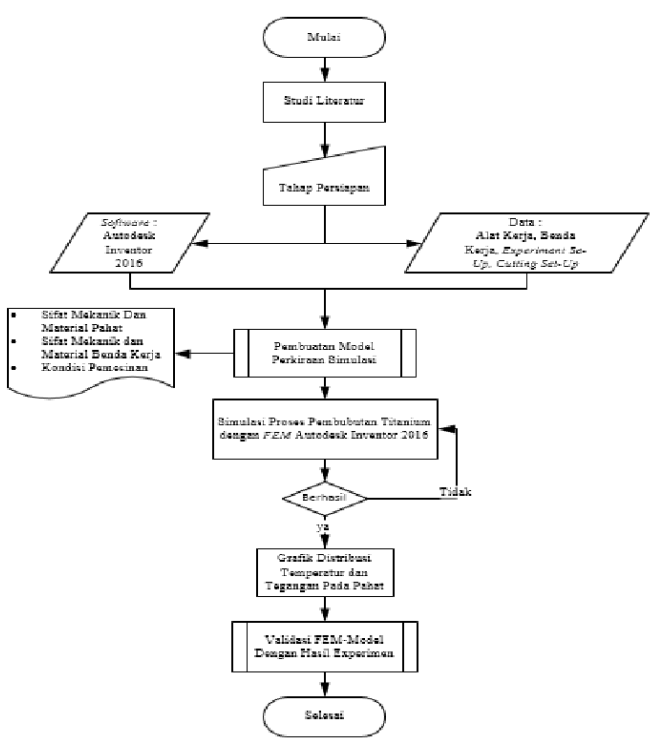

Gambar 1 Diagram Alir Simulasi.

Finite Element Analysis adalah suatu cara untuk mendapatkan hasil eksperimen yang mendekati situasi atau keadaan yang sebenarnya dengan bantuan dengan bantuan komputer, dimana dalam melakukan penelitian ini menggunakan bantuan Software Autodek Inventor 2016.

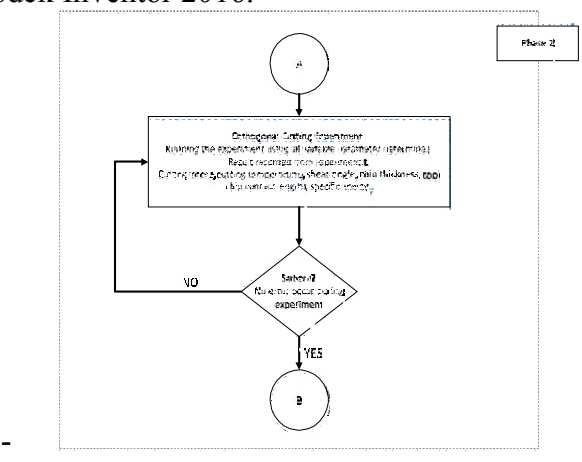

Gambar 2 Diagram Alir Penelitian
Tabel 1 menunjukan kondisi batas yang ditentukan berdasarkan beberapa penelitian sebelumnya. Hal ini dilakukan untuk mendapatkan hasil yang baik dalam rentang kondisi tertentu.

Tabel 1. Kondisi Batas Pemesinan

\begin{tabular}{|c|c|}
\hline $\begin{array}{l}\text { Kondisi } \\
\text { Batas } \\
\text { Penelitian }\end{array}$ & Deskripsi \\
\hline $\begin{array}{l}\text { Parameter } \\
\text { Pemesinan }\end{array}$ & $\begin{array}{l}\text { Cutting Speed, } \mathrm{V}_{\mathrm{c}}(\mathrm{m} / \mathrm{min})= \\
350 \\
\text { Feed Rate, } \mathrm{F}_{\mathrm{r}}(\mathrm{mm} / \mathrm{rev})=0.10 \\
\text { Depth of cut }, \mathrm{d}(\mathrm{mm})=1 \mathrm{~mm}\end{array}$ \\
\hline Pendingin & $\mathrm{SCCO}_{2}$ \\
\hline Pahat & $\begin{array}{l}\text { Tools }=\text { Uncoated Carbide } \\
\text { Rake Angle }=5^{\circ}, 10^{\circ}, 15^{\circ}\end{array}$ \\
\hline $\begin{array}{l}\text { Parameter } \\
\text { Pendingin }\end{array}$ & $\begin{array}{l}\text { Temperature }=-80^{\circ} \\
\text { Chamber pressure }=10.34 \mathrm{MPa} \\
\text { Nozzle distance }=8 \mathrm{~mm} \\
\text { Nozzle angle }=45^{\circ} \\
\text { Lubricant flow rate }=2.61 \mathrm{1} / \mathrm{hr}\end{array}$ \\
\hline
\end{tabular}

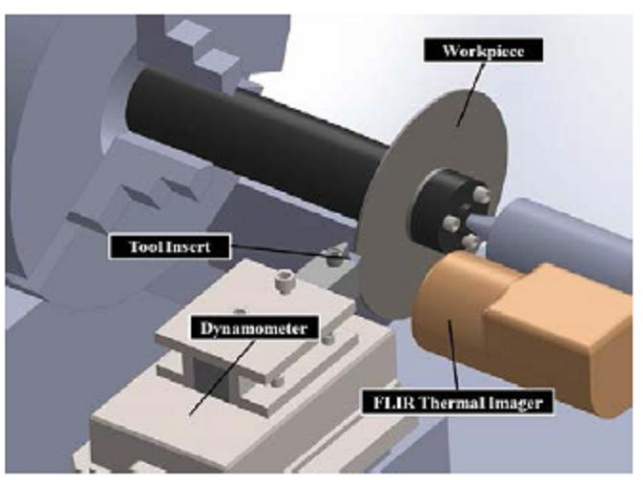

Gambar 3. Kondisi pemesinan [2]

\section{Langkah-langkah Analisis}

Finite Element Analysis merupakan adalah suatu cara untuk mendapatkan hasil eksperimen yang mendekati situasi atau keadaan yang sebenarnya dengan bantuan dengan bantuan komputer, dimana dalam melakukan penelitian ini menggunakan bantuan Software Autodek Simulation Mechanical 2016. Tahapan-tahapan tersebut dapat diuraikan sebagai berikut:

1. Pembuatan model prakiraan simulasi proses pembubutan titanium menggunakan Autodesk Inventor 2016 perlu mempertimbangkan beberapa parameter, seperti geometri dan sifat 
mekanik pahat dan benda kerja serta beban yang diberikan berupa gaya potong yang timbul pada sudut kontak antara pahat dan benda kerja.

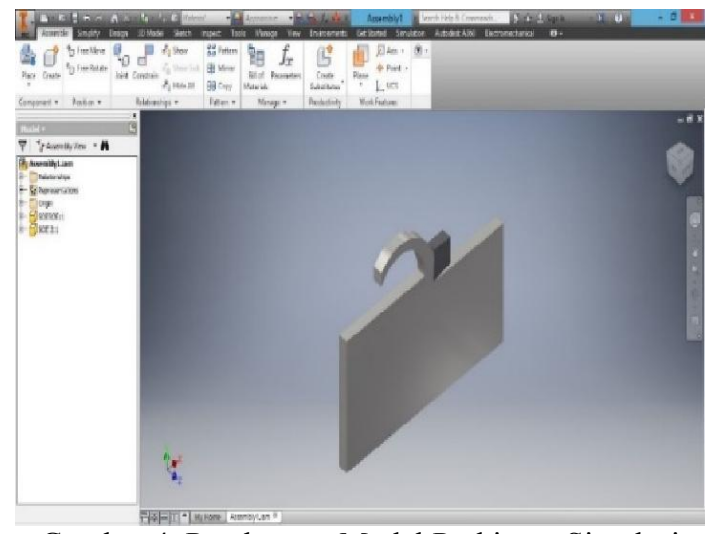

Gambar 4. Pembuatan Model Prakiraan Simulasi Menggunakan Autodesk Inventor 2016

2. Penentuan kondisi batas dilakukan setelah model prakiraan diberikan beban kerja. Dalam penulisan ini kondisi batas yang diberikan adalah kondisi pemesinan pada proses pembubutan titanium.

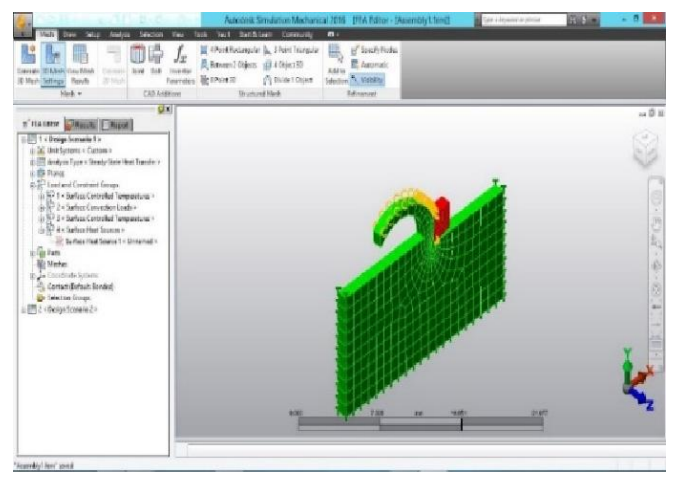

Gambar 5. Tampilan Mesh view dan batas kondisi prakiraan simulasi menggunakan Autodesk Simulation Mechanical 2016

3. Hasil yang didapatkan pada penelitian ini berupa grafik tegangan yang terjadi pada proses pemesinan titanium.

4. Tahapan terakhir adalah melakukan validasi hasil simulasi dengan hasil eksperimen.

\section{HASIL DAN PEMBAHASAN}

\section{Parameter Pemesinan}

Parameter pemesinan yang digunakan pada proses simulasi ini mengacu pada penelitian yang telah dilakukan oleh (Rahim et al. 2016) seperti ditunjukan pada Tabel 1

\section{Data Hasil Perhitungan}

Adapun data simulasi pemotongan seperti ditunjukan pada bab sebelumnya, dapat ditentukan menggunakan persamaan, sehingga didapatkan hasil sebagai berikut (Tabel 2).

Tabel 2. Data hasil perhitungan

\begin{tabular}{|c|c|c|c|}
\hline Rake Angle & $5^{\circ}$ & 10 & 15 \\
\hline $\begin{array}{c}\text { Shear Angle } \\
\phi\end{array}$ & 43 & 40 & 37 \\
\hline $\begin{array}{c}\text { Chip } \\
\text { Thickness } \\
\text { Ratio }\end{array}$ & $0.8655 \mathrm{~mm}$ & $0.7422 \mathrm{~mm}$ & $0.6490 \mathrm{~mm}$ \\
\hline t2 & $1.1554 \mathrm{~mm}$ & $1.3473 \mathrm{~mm}$ & $1.5408 \mathrm{~mm}$ \\
\hline Shear Strain & 1.8535 & 1.769 & 1.731 \\
\hline $\begin{array}{c}\text { Shear Force } \\
\text { (Fs) }\end{array}$ & 1114.37 & 1182.35 & 1262.84 \\
\hline $\begin{array}{c}\text { Cutting Force } \\
\text { (Fc) }\end{array}$ & $1720.73 \mathrm{~N}$ & $1590.04 \mathrm{~N}$ & $1521.172 \mathrm{~N}$ \\
\hline \multicolumn{2}{|c|}{} & & \\
\hline
\end{tabular}

\section{Pemodelan Benda Kerja dan Pahat}

Sebelum melakukan tahap simulasi penulis melakukan pembuatan sketsh simulasi di Autodesk Inventor 2016 dengan mengklik tab "Get Started > New $>$ Metric $>$ Standard $(\mathrm{mm})$.ipt $>$ lalu klik

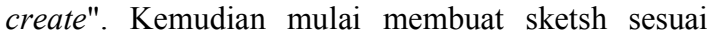
dengan dimensi yang mengacu pada penelitian yang telah dilakukan oleh [7] seperti ditunjukan pada Tabel 3 di bawah ini

Tabel 3. Analysis conditions for cutting simulation [6]

\begin{tabular}{|c|c|}
\hline \multicolumn{2}{|c|}{ Benda Kerja } \\
\hline Cutting depth & $1 \mathrm{~mm}$ \\
\hline Cutting distance & $9 \mathrm{~mm}$ \\
\hline Workpiece length & $10 \mathrm{~mm}$ \\
\hline Rake angle & $5^{\circ} 10^{\circ} 15^{\circ}$ \\
\hline Clearance angle & $12^{\circ}$ \\
\hline \multicolumn{2}{|c|}{ Pahat } \\
\hline Tool height & $2 \mathrm{~mm}$ \\
\hline Tool thickness & $2 \mathrm{~mm}$ \\
\hline Tool width & $1 \mathrm{~mm}$ \\
\hline $\begin{array}{l}\text { Room } \\
\text { Temperature }\end{array}$ & $27^{\circ} \mathrm{C}$ \\
\hline
\end{tabular}




\section{Setup Simulasi}

Setelah model selesai di eksport ke Autodesk Simulation Mechanical 2016 langkah selanjutya pemilihan analysis type. Pemilihan analysis type ini bertujuan untuk menentukan jenis analisis apa yang akan digunakan. Pada kasus ini analysis type yang dipilih adalah "Static Stress with Linear Material Model'.

\section{Meshing}

Setelah pemilihan analysis type, model akan terbuka pada layar Autodesk Simulation Mechanical 2016, langkah berikutnya adalah pemberian meshing pada model. Masuk ke tab Mesh > panel Mesh > Generate 3D Mesh, untuk membuat mesh pada model kita. Seperti diperlihatkan pada Gambar 6 dibawah ini.

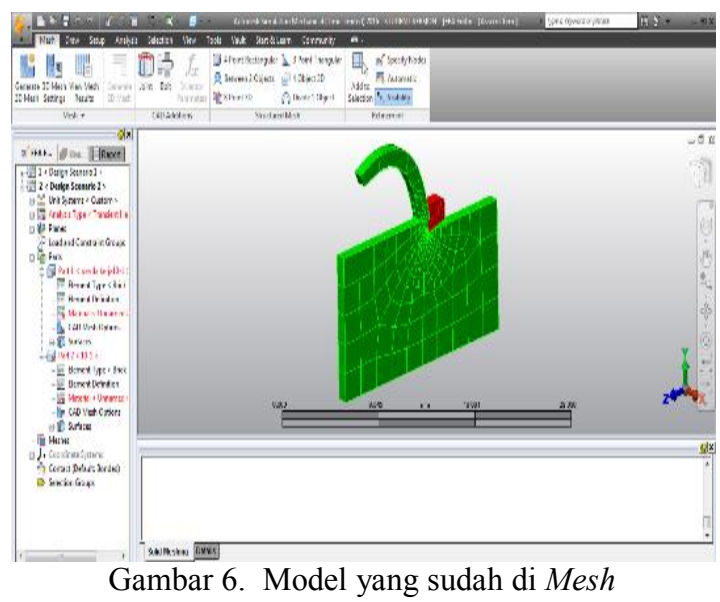

\section{Setup Simulasi}

Setelah mesh terbentuk, langkah berikutnya adalah memberikan material pada setiap model. Pada browser FEA Editor, yang terletak pada bagian sebelah kiri layar, pilih salah satu part $>$ material $>$ Klik kanan $>$ pilih edit untuk memberikan material pada model yang kita pilih.

Setelah mengklik edit material maka akan terbuka layar element material selection seperti ditunjukan pada dibawah ini. Selanjutnya klik edit properties dan masukan nilai material properties sesuai dengan material yang akan digunakan. Material properties yang digunakan pada model simulasi ini dapat dilihat pada Gambar 7

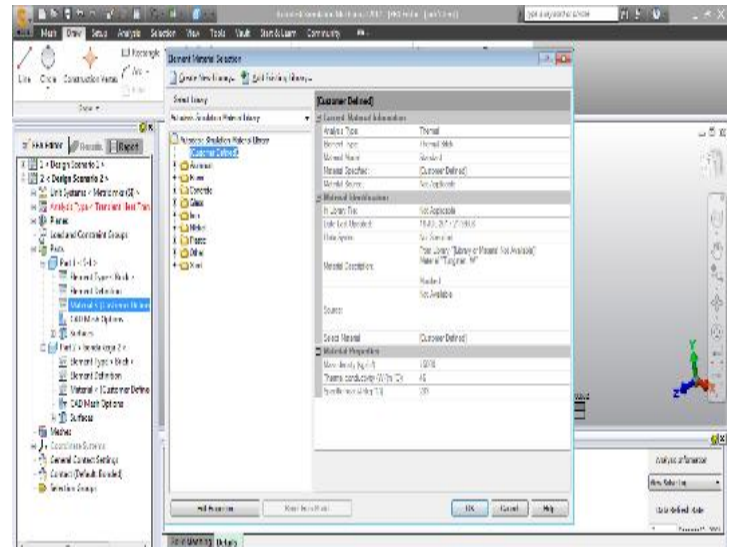

Gambar 7. Element Material Selection

Tabel 4. Properties of Tungsten Carbide

\begin{tabular}{ll}
\hline Density & $19300 \mathrm{~kg} / \mathrm{m}^{3}$ \\
Elastic Modulus & $40 \times 10^{10}$ \\
Hardness & $3600 \mathrm{Mpa}$ \\
\hline
\end{tabular}

Tabel 5. Properties of Titanium Ti-6Al-4V (Ginting 2006)

\begin{tabular}{ll}
\hline Density & $4430 \mathrm{~kg} / \mathrm{m}^{3}$ \\
Hardness & $3334 \mathrm{Mpa}$ \\
Elastic Modulus & $1138 \times 10^{8}$ \\
Shear Strength & $760 \mathrm{n} / \mathrm{mm}^{2}$ \\
Yield Strength $\left(\sigma_{\mathrm{y}}\right)$ & $1070 \mathrm{~N} / \mathrm{mm}^{2}$ \\
Fatigue Strength $\left(\sigma_{\mathrm{w}}\right)$ & $580 \mathrm{~N} / \mathrm{mm}^{2}$ \\
\hline
\end{tabular}

\section{Parameter Analisis}

Langkah berikutnya adalah memberikan parameters analysis pada simulasi. dengan mengklik tab "Analysis type $>$ Edit Analysis Type $>$ Thermal > Another Design Scenario in loaded file di Source of Temperature $>$ Masukkan nilai $27^{\circ}$ di Tab Default Temperature $>$ Pilih Design Scenario di Use Temperature from Design Scenario $>$ OK. Maka akan muncul Gambar 8 .

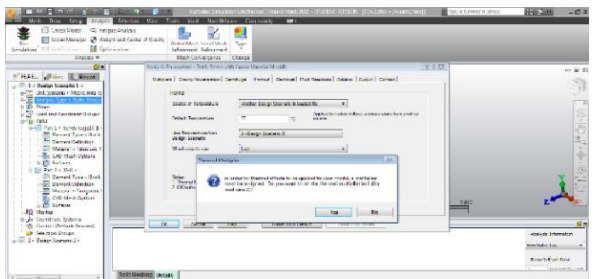

Gambar 8. Tampilan Setelah menentukan Parameter 
Analysis

Kemudian masukkan gaya potong $\left(\mathrm{F}_{\mathrm{c}}\right)$ yang sudah didapat di Tabel 2 dengan cara pilih bidang yang akan diberikan gaya Klik kanan $>$ Add > Surface Force $>$ Masukkan nilai $\mathrm{F}_{\mathrm{c}}$ sesuai Tabel 2> OK

\section{Menjalankan Simulasi}

Jika sudah selesai memberikan seluruh boundary condition dan menentukan parameters analysis, langkah selanjutnya adalah menjalankan analisis untuk membuat simulasi. Pada tab "Analysis" $>$ panel "Analysis" > klik "Run Simulation" untuk memulai analisis.

\section{Hasil Simulasi}

Setelah proses run simulation maka dapat kita lihat hasil dari simulasi proses pembubutan Ti-6Al$4 \mathrm{~V}$ untuk melihat Tegangan pada tool berikut ini.
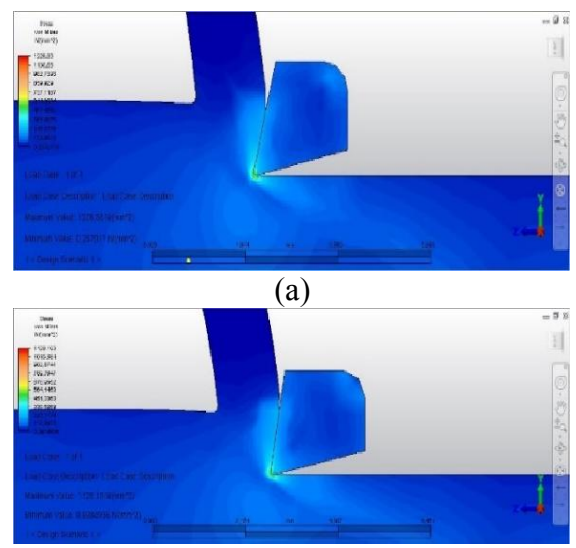

(b)

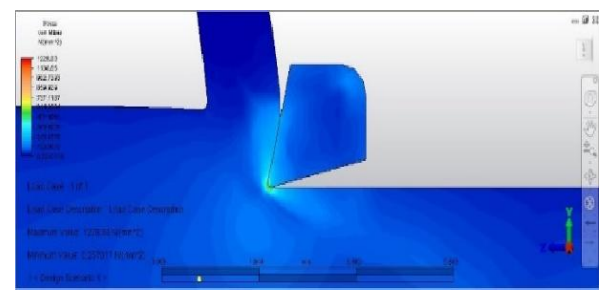

(c)

Gambar 9. Posisi pahat saat memotong benda kerja

(a) Geram $(\gamma) 5^{\circ}$, (b) Geram $(\gamma) 10^{\circ}$ (c) Sudut Geram $(\gamma) 15^{\circ}$

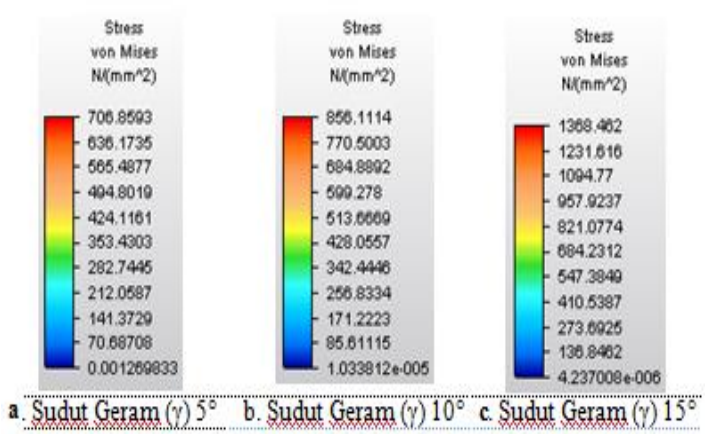

Gambar 10. Perbandingan tegangan pada tiap sudut

\section{Pembahasan}

Berdasarkan dari perhitungan manual didapatkan hasil variasi Rake Angle terhadap Chip Thickness yaitu, $1.1554 \mathrm{~mm}$ untuk Sudut Geram $5^{\circ}$, $1.3473 \mathrm{~mm}$ untuk Sudut Geram $10^{\circ}$ dan $1.5408 \mathrm{~mm}$ untuk Sudut Geram $15^{\circ}$. Sedangkan hasil simulasi yang didapat perbandingan tegangan untuk Rake Angle yang berbeda selama proses pembubutan Ti$6 \mathrm{Al}-4 \mathrm{~V}$ dengan kedalaman potong $1 \mathrm{~mm}$ menggunakan pahat karbida menghasilkan nilai tegangan maksimum yang berbeda yaitu 706.8593 $\mathrm{N} / \mathrm{mm}^{2}$ untuk Sudut Geram $(\gamma) 5^{\circ}, 856.1114 \mathrm{~N} / \mathrm{mm}^{2}$ untuk Sudut Geram $(\gamma) 10^{\circ}$ dan $1368.462 \mathrm{~N} / \mathrm{mm}^{2}$ untuk Sudut Geram $(\gamma) 15^{\circ}$ dimana berbanding terbalik dengan Gaya Potong $\left(\mathrm{F}_{\mathrm{c}}\right)$ yaitu $1720.73 \mathrm{~N}$ untuk Sudut Geram $(\gamma) 5^{\circ}, 1590.04 \mathrm{~N}$ untuk Sudut Geram $(\gamma) 10^{\circ}$ dan $1521.172 \mathrm{~N}$ untuk Sudut Geram $(\gamma) 15^{\circ}$, terjadi penurunan Gaya Potong $\left(F_{c}\right)$ untuk setiap kenaikan Sudut Geram $(\gamma)[3,5]$. Kenaikan tegangan ini bisa karena panjang kontak antara geram dan pahat dimana bisa berakibat kenaikan temperatur mengakibatkan tegangan naik.

\section{KESIMPULAN}

Kesimpulan yang diperoleh dari penelitian dan pembahasan mengenai analisa distribusi Temperatur pahat pada proses pembubutan titanium dengan FEM-Simulation menggunakan Software Autodesk Simulation Mechanical 2016, maka dapat diambil kesimpulan sebagai berikut:

1. Dari perhitungan secara teoritis diketahui bahwa gaya Potong $\left(\mathrm{F}_{\mathrm{c}}\right)$ yaitu $1720 \mathrm{~N}$ untuk sudut geram $(\gamma) 5^{\circ}, 1589 \mathrm{~N}$ untuk Sudut Geram $(\gamma) 10^{\circ}$ dan $1520 \mathrm{~N}$ untuk Sudut Geram $(\gamma) 15^{\circ}$, terjadi penurunan Gaya Potong $\left(\mathrm{F}_{\mathrm{c}}\right)$ untuk setiap kenaikan Sudut Geram $(\gamma)$.

2. Berdasarkan hasil simulasi nilai tegangan maksimum yaitu $706.8593 \mathrm{~N} / \mathrm{mm}^{2}$ untuk Sudut Geram $(\gamma) 5^{\circ}, 856.1114 \mathrm{~N} / \mathrm{mm}^{2}$ untuk Sudut Geram $(\gamma) 10^{\circ}$ dan $1368.462 \mathrm{~N} / \mathrm{mm}^{2}$ untuk Sudut 
Geram $(\gamma) 15^{\circ}$, terjadi kenaikan tegangan untuk setiap kenaikan Sudut Geram $(\gamma)$.

3. Perbandingan analisa gaya pada jurnal acuan dan analisa secara teoritis mengalami perbedaan yang tidak terlalu jauh pada proses pemesinan Cryogenic ini. Dimana gaya pada jurnal acuan untuk pemotongan baja karbon AISI 1045 untuk sudut geram untuk Sudut Geram $(\gamma) 5^{\circ}$ adalah $553 \mathrm{~N}$ dengan kekerasan yang lebih rendah dari Ti-6Al-4V [6].

\section{DAFTAR RUJUKAN}

[1] Kalpakjian, S. \& Schimd, S.R., 2001. Manufacturing Engineering and Technology Forth Edition 4th ed., Hongkong \& Macau: Higher Education Press.

[2] Rahim, E.A. et al., 2016. Experimental Investigation of Supercritical Carbon Dioxide ( SCCO 2 ) Performance as a Sustainable
Cooling Technique. Procedia CIRP, 40, pp.637-641.

[3] Rochim, T., 2007. Perkakas \& Sistem Pemerkakasan 2nd ed., Bandung: ITB.

[4] Shoujin, S. et al., 2015. Effects of cryogenic compressed air on the evolution of cutting force and tool wear during machininf of Ti-6Al-4V alloy. Materials Procesing Technology.

[5] Boothroyd,G. \& Knight, W.A., 1989. Fundamentals Of Machining And Machine Tools 2nd ed., New York: Marcel Dekker.

[6]. Hyatt, J., 1984. Liquid and supercritical carbon dioxide as organic solvents. Organic Chemistry.

[7] Rochim, T., 1993. Proses Pemesinan, Jakarta: Erlangga. 